\title{
Modeling and Optimal Control of Heavy-Duty Powertrains
}

\author{
Vaheed Nezhadali
}

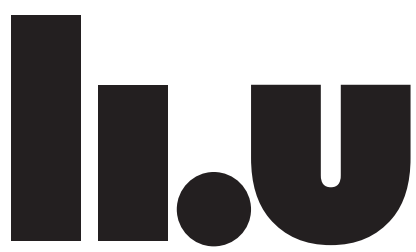

LINKÖPINGS UNIVERSITET

Department of Electrical Engineering

Linköping University

SE-581 83 Linköping, Sweden

Linköping 2016 
Linköping studies in science and technology. Dissertations, No. 1771

\section{Modeling and Optimal Control of Heavy-Duty Powertrains}

Vaheed Nezhadali

ISBN 978-91-7685-748-9

ISSN 0345-7524

(C) 2016 Vaheed Nezhadali, unless otherwise noted. All rights reserved.

Vaheed Nezhadali

vaheed.nezhadali@liu.se

www. vehicular.isy.liu.se

Division of Vehicular Systems

Department of Electrical Engineering

Linköping University

SE-581 83 Linköping

Sweden

The cover: The background photo on the cover shows the Roxen lake with Linköping on it's horizon. At the begining of my very first presentation in Linz 2013, I introduced the city of my studies with this picture. I wanted to finish with the same picture which will remind me of my 7 years in Linköping whenever I look at this dissertation. The graphic figure on top of the background, shows the feasible regions of operation for two subsystems, and two sets of state trajectories. More about this is described at the end of chapter 2 .

Typeset with $\mathrm{HT}_{\mathrm{EX}} 2 \varepsilon$

Printed by LiU-Tryck, Linköping, Sweden 2016 
To Samira and my parents 



\section{Abstract}

Heavy duty powertrains are complex systems with components from various domains, different response times during transient operations and different efficient operating ranges. To ensure efficient transient operation of a powertrain, e.g. with low fuel consumption or short transient duration, it is important to come up with proper control strategies. In this dissertation, optimal control theory is used to calculate and analyze efficient heavy duty powertrain controls during transient operations in different applications. This is enabled by first developing control ready models, usable for multi-phase optimal control problem formulations, and then using numerical optimal control methods to calculate the optimal transients.

Optimal control analysis of a wheel loader operating in a repetitive loading cycle is the first studied application. Increasing fuel efficiency or reducing the operation time in such repetitive loading cycles sums up to large savings over longer periods of time. Load lifting and vehicle traction consume almost all of the power produced by a diesel engine during wheel loader operation. Physical models are developed for these subsystems where the dynamics are described by differential equations. The model parameters are tuned and fuel consumption estimation is validated against measured values from real wheel loader operation. The sensitivity of wheel loader trajectory with respect to constrains such as the angle at which the wheel loader reaches the unloading position is also analyzed. A time and fuel optimal trajectory map is calculated for various unloading positions. Moreover, the importance of simultaneous optimization of wheel loader trajectory and the component transients is shown via a side to side comparison between measured fuel consumption and trajectories versus optimal control results.

In another application, optimal control is used to calculate efficient gear shift controls for a heavy duty Automatic Transmission system. A modeling and optimal control framework is developed for a nine speed automatic transmission. Solving optimal control problems using the developed model, time and jerk efficient transient for simultaneous disengagement of off-going and engagement of in-coming shift actuators are obtained and the results are analyzed.

Optimal controls of a diesel-electric powertrain during a gear shift in an Automated Manual Transmission system are calculated and analyzed in another application of optimal control. The powertrain model is extended by including driveline backlash angle as an extra state in the system. This is enabled by implementation of smoothing techniques in order to describe backlash dynamics as a single continuous function during all gear shift phases.

Optimal controls are also calculated for a diesel-electric powertrain corresponding to a hybrid bus during a tip-in maneuver. It is shown that for optimal control analysis of complex powertrain systems, minimizing only one property such as time pushes the system transients into extreme operating conditions far from what is achievable in real applications. Multi-objective optimal control problem formulations are suggested in order to obtain a compromise between various objectives when analyzing such complex powertrain systems. 


\section{Populärvetenskaplig sammanfattning}

Denna avhandling bygger matematiska modeller för olika delar av kommersiella fordon och utvecklar metoder som tar hjälp av optimering och visar hur man mest effektivt skall utnyttja drivlinor och fordon i olika arbetssekvenser. Med effektivt avses både låg bränsleförbrukning och korta arbetstider så att det blir både milljömässigt och tidsmässigt effektivt för en användare. Metodmässigt har vi jobbat på att ta fram metodik för att snabbt och effektivt ta fram olika optimala körtrajektorier för ett flertal tillämpningar genom att använda state-of-the-art verktyg inom optimal styrning. Tekniskmässigt spänner den över områden från turbo och motorteknik, via mekaniska och elektrifierade drivlinor och växellådor upp till dynamik och rörelse för kompletta fordon. För motor och turbo har visats hur viktigt det är att ta hänsyn till turbosystemets dynamik i optimeringar och utvärderingar av optimala körtrajektorier. För växellådor visades hur man optimalt skall växla för bra komfort och korta växlingstider samt låg energiförbrukning, samt visats hur en elmaskin i hybridfordon kan användas för att sänka bränsleförbrukningen och förbättra växlingskomforten och snabbheten vid växlingsbyten. För helt fordon så har optimala körbanor som visar hur man optimalt skall köra en hjullastare tagits fram då man lastar t.ex. en dumper eller lastbil, i analysen behandlas alla komponenter från motorn och turbon, lyftsystemet, växellådan med momentomvandlare, samt fordonets styrning och rörelse över marken från lastupptagningsplatsen till lastmottagaren. 


\section{Acknowledgment}

During the last five years, I have spent most of my time reading and writing papers, taking courses and generally trying to learn more about optimal control, powertrains and transmission systems. However, these activities are not the main picture that I will carry in mind when I think about my time at vehicular systems (FS). I entered the group as one of the very first foreigners and it took me some time to optimally control my path into becoming familiar with the environment. In this process, all former and current FS employees contributed by forming such positive working atmosphere and I am thankful to every single one of them. I think I have been lucky to enter the Swedish working environment in such a group and this is what I will have in mind about FS in future.

Nevertheless, there are some people whom I'd like to thank specifically. I should first of all thank Lars Nielsen for giving me the chance to start at FS, first as a research engineer and then as a $\mathrm{PhD}$ student. I gratefully acknowledge my supervisor Lars Eriksson who effectively guided me by being available for discussions and supervision meetings in earlier years, and also letting me develop an independent and responsible character by giving me more freedom in the later years. I specially thank Martin Sivertsson who was my patient office-mate when I started speaking Swedish, a wise grandfather good at foreseeing possible risks in everything, and generally a good friend ready to talk about anything at any time. I should also thank Xavi Llamas for being a loyal football companion at levels close to the La Liga standards. Kristoffer Lundahl is thanked for bringing me a souvenir from my favorite region of the world, and moreover, proving to me that EVERY thing about a trip can be fixed in the very last minute (or even seconds!). Kristoffer Ekberg is also acknowledged for proof reading the introductory chapters of this dissertation.

There are also persons whom I lack words to express my gratitude to them. The first in the list is Samira, who has been and will ever remain my love and best friend; I thank you for your patience and support during the last 10 years of our lives. My most sincere gratitude goes to my parents. As I grow older and see more of the world, I find more and more about all scarifies and hard work they have ever gone through to see their children succeeding.

Linköping, May 2016

Vaheed Nezhadali 


\section{Contents}

1 Introduction $\quad \mathbf{3}$

1.1 Wheel loader operation in a loading cycle . . . . . . . . . . . . 4

1.2 Gear shift control in heavy duty powertrain . . . . . . . . . . . . 6

1.3 Summary and contributions of the papers included in the thesis . . . . 7

2 On modeling and optimal control of heady duty powertrains $\quad \mathbf{1 3}$

2.1 Wheel loader modeling and control . . . . . . . . . . . . . . . 13

2.2 Modeling for AT gear shift control . . . . . . . . . . . . . . 16

2.3 Modeling for AMT gear shift control . . . . . . . . . . . . . . . . . 17

2.4 Solving optimal control problems . . . . . . . . . . . . . . . . 18

$\begin{array}{ll}\text { References } & 20\end{array}$

$\begin{array}{ll}\text { Papers } & 29\end{array}$

1 Modeling and optimal control of a wheel loader in the lift-transport $\begin{array}{ll}\text { section of the short loading cycle } & 31\end{array}$

1 Introduction . . . . . . . . . . . . . . . . . 33

2 Wheel loader system model . . . . . . . . . . . . . . . . . 34

3 Problem formulation . . . . . . . . . . . . . . . . . . . . 38

4 Results . . . . . . . . . . . . . . . . . . . . 40

5 Conclusion . . . . . . . . . . . . . . . . . . . 44

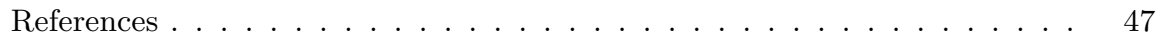

2 Optimal control of wheel loader operation in the short loading cycle $\begin{array}{ll}\text { using two braking alternatives } & 49\end{array}$

1 Introduction . . . . . . . . . . . . . . . . . . . . . 51 
$2 \quad$ System model . . . . . . . . . . . . . . . . . . . . 52

3 Problem formulation . . . . . . . . . . . . . . . . . 57

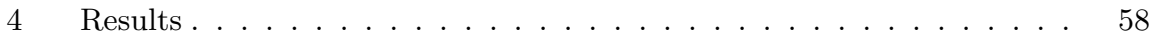

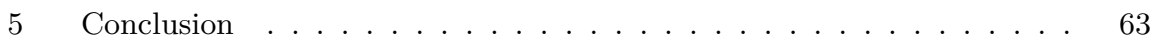

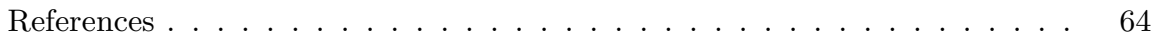

3 Optimal lifting and path profiles for a wheel loader considering engine and turbo limitations $\quad \mathbf{6 5}$

1 Introduction . . . . . . . . . . . . . . . . . . . 67

2 System model . . . . . . . . . . . . . . . . . . . . 68

3 Optimal control problem formulation . . . . . . . . . . . . . 75

$4 \quad$ Results . . . . . . . . . . . . . . . . . . . 77

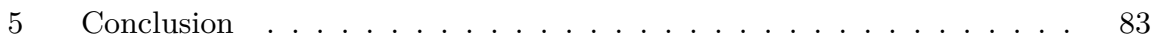

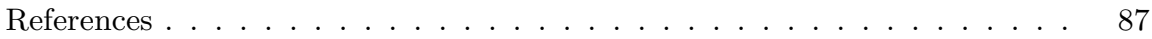

4 Wheel loader optimal transients in the short loading cycle $\quad 89$

1 Introduction . . . . . . . . . . . . . . . . . . . . . 91

2 Wheel loader system model . . . . . . . . . . . . . . . . . . . 92

3 Problem formulation . . . . . . . . . . . . . . . . . . . . . 94

4 Optimization results . . . . . . . . . . . . . . . . 96

5 Conclusion . . . . . . . . . . . . . . . . . . . . 101

References . . . . . . . . . . . . . . . . . . . . . 104

5 Turbocharger dynamics influence on optimal control of diesel engine $\begin{array}{lr}\text { powered systems } & 105\end{array}$

1 Introduction . . . . . . . . . . . . . . . . . . . . 107

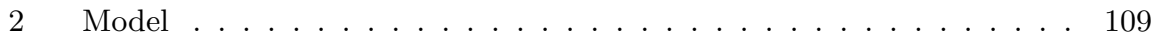

3 Problem Formulation . . . . . . . . . . . . . . . . . . . . . 112

$4 \quad$ Results . . . . . . . . . . . . . . . . . . . . . . . . . 114

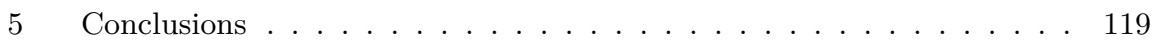

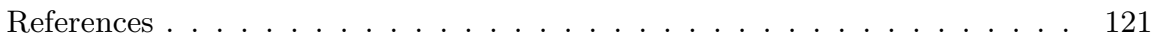

6 A framework for modeling and optimal control of automatic trans$\begin{array}{lr}\text { mission systems } & 123\end{array}$

1 Introduction . . . . . . . . . . . . . . . . . . . . 125

2 Driveline model . . . . . . . . . . . . . . . . . . . 126

3 Optimal Control Problem formulation . . . . . . . . . . . . . . . . 133

4 Optimal control results . . . . . . . . . . . . . . . . . . . 135

5 Conclusion . . . . . . . . . . . . . . . . . . . . 139

References . . . . . . . . . . . . . . . . . . . . . 140

7 Wheel loader operation-optimal control compared to real drive experience

1 Introduction . . . . . . . . . . . . . . . . . . . 146

2 Measurement setup . . . . . . . . . . . . . . . . . . . . . . 148

3 Optimal control setup . . . . . . . . . . . . . . . . . . . 151

$4 \quad$ Results and discussion . . . . . . . . . . . . . . . . . . . 157

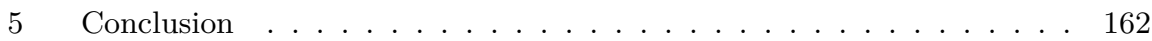

References . . . . . . . . . . . . . . . . . . . 164 
8 Optimal control of a diesel-electric powertrain during an up-shift $\mathbf{1 6 7}$

1 Introduction . . . . . . . . . . . . . . . . . . 169

2 Powertrain model . . . . . . . . . . . . . . . . . . . 171

3 Optimal control problem formulation . . . . . . . . . . . . . . . 174

4 Optimal control results . . . . . . . . . . . . . . . . . . . 177

5 Conclusions . . . . . . . . . . . . . . . . . . . . . . 181

References . . . . . . . . . . . . . . . . . . . . 182

9 Optimal control of engine controlled gearshift for a diesel-electric $\begin{array}{lc}\text { powertrain with backlash } & 183\end{array}$

1 Introduction . . . . . . . . . . . . . . . . . . . . . . 184

2 Powertrain model . . . . . . . . . . . . . . . . . . . . . . . 185

3 Optimal control problem formulation . . . . . . . . . . . . . . . . 192

$4 \quad$ Results . . . . . . . . . . . . . . . . . . . . . . 194

$5 \quad$ Conclusions . . . . . . . . . . . . . . . . . . . 199

References . . . . . . . . . . . . . . . . . . . . . 200

10 Analysis of optimal diesel-electric powertrain transients during a tip$\begin{array}{lr}\text { in maneuver } & 201\end{array}$

1 Introduction . . . . . . . . . . . . . . . . . . . . . 202

2 Powertrain model . . . . . . . . . . . . . . . . . . . . . . 203

3 Problem formulation . . . . . . . . . . . . . . . . . . . . 204

4 Optimal control results . . . . . . . . . . . . . . . . 207

5 Conclusions . . . . . . . . . . . . . . . . . . . . . . . . . . . 214

References . . . . . . . . . . . . . . . . . . . 215 



\section{Introduction}





\section{Introduction}

Industrializations of countries and the high rate of energy consumption in the industrial societies have left no doubt that we need to be more efficient in using natural fossil fuel resources. Transportation systems are a major consumer of fossil fuels with a considerable contribution from heavy duty commercial vehicles. Governments are enforcing new regulations to reduce the usage of fossil fuels in order to ensure sustainable and environmentally friendly transportation systems. As an example, Sweden has a vision of reducing the dependency of its transportation fleet on fossil fuels to achieve zero emissions in 2050 with the priority of having fossil free transportation by 2030, for details see [10]. To meet such new stringent regulation requirements, development of new control strategies or devising new powertrain systems such as electrified powertrains are inevitable.

The rapid growth of computers' computational power has opened up new opportunities to develop and implement novel control strategies for complex systems. Moreover, in order to fulfill the regulated requirements during vehicle operations at different regions of the world, control strategies covering wider range of operating conditions are favored by manufacturers. By early 1970's, the idea of using a process model to control a system was widely accepted among industries, [11]. Classical control techniques, based on look-up tables describing the system behavior under various conditions, are limited to the range of available data in the tables. However, model based control techniques such as adaptive control or model predictive control have extrapolation capabilities and therefore are becoming more attractive for industries, see [6] and [12].

Designing efficient model based control strategies for powertrain systems and specifically diesel engines is not a trivial task due to system complexities. Most of the times, the powertrain is comprised of various subsystems and components with different efficient range of operation, different response time 
during transients and subsystems with non-minimum phase behavior. Numerous research papers are available on this topic and some few examples are [2], [22], [35], [37] and [84].

To gain an insight about how efficient controls and the corresponding system transients should look like, Optimal Control (OC) theory is an effective tool. Same models used in model based control with slight modifications can be used in $\mathrm{OC}$ analysis and thanks to the ever increasing computational power of computers; it is possible to analyze even complex and nonlinear systems using numerical OC methods. These types of analyses are attractive in the case of heavy duty applications since fewer regulated benchmarking standards exist for control of the operations using such powertrain systems.

This dissertation presents some applications of OC methods for optimization of heavy duty powertrain transients during various operations. The term powertrain here refers to all of the components involved in power production and transfer. Two major groups of applications are considered where for each application, first control ready models are developed to enable formulation of OC problem for desired scenarios. In the first studied application, operation of a wheel loader during a repetitive loading cycle is analyzed with the aim to obtain OCs for time and fuel efficient operation of the wheel loader. In the second group, modeling and OC analysis is performed with the aim to obtain efficient gear shift controls in Automatic Transmission (AT) and Automated Manual Transmission (AMT) systems.

\section{Dissertation outline}

In the following sections of this chapter, first the powertrain systems studied in the dissertation are introduced. Then a summary of all papers included in the dissertation and the contribution of each paper to the field of modeling and OC of heavy duty powertrains is presented. In the next chapter, powertrain system models and important modeling aspects are briefly introduced. Some practical issues arising when OC problems are formulated and solved are also presented. After the second chapter, the published papers are appended presenting the details of the dissertation contribution to the modeling and OC field.

\subsection{Wheel loader operation in a loading cycle}

Wheel loaders frequently operate in repetitive material handling processes referred to as Short Loading Cycle (SLC). Figure 1.1 illustrates the layout of the operation in an SLC and different phases of the process are described in Table 1.1. Wheel loaders are widely used at construction sites all over the world and there is a strong desire from both wheel loader manufacturers and owners to come up with solutions for fuel consumption reduction and faster operation of these machines. During wheel loader operation, operator decisions about control of diesel engine and vehicle speed, load lifting, and steering has direct effects on fuel consumption and duration of SLC. 


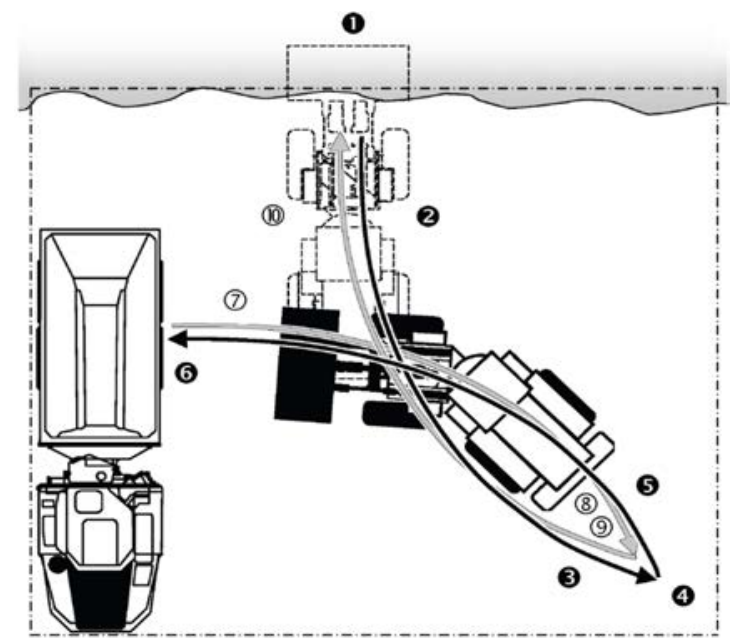

Figure 1.1: Numbered sequence of different phases in a short loading cycle, picture from $[20]$.

Table 1.1: Short loading cycle phases, according to [20].

\begin{tabular}{|c|c|c|}
\hline \# & phase & Action \\
\hline 1 & Bucket filling & $\begin{array}{l}\text { Control of vehicle speed, } \\
\text { bucket lift-tilt functions. }\end{array}$ \\
\hline 2 & Leaving bank & $\begin{array}{l}\text { Control of vehicle speed, steering in } \\
\text { a V-pattern, possible lifting. }\end{array}$ \\
\hline 3 & Speed reduction & $\begin{array}{l}\text { Control of vehicle speed to stop at } \\
\text { reversing point, steering, gear change. }\end{array}$ \\
\hline 4 & Reversing & $\begin{array}{l}\text { Possible gear change, adjusting } \\
\text { steering angle to meet the load receiver. }\end{array}$ \\
\hline 5 & Towards load receiver & $\begin{array}{l}\text { Control of vehicle speed, steering in } \\
\text { a V-pattern, possible lifting. }\end{array}$ \\
\hline 6 & Bucket emptying & $\begin{array}{l}\text { Control of vehicle speed, } \\
\text { bucket lift-tilt functions. }\end{array}$ \\
\hline 7 & Leaving load receiver & $\begin{array}{l}\text { Control of vehicle speed, } \\
\text { steering in a V-pattern, lowering bucket. }\end{array}$ \\
\hline 8 & $\begin{array}{l}\text { Speed reduction } \\
\text { and reversing }\end{array}$ & $\begin{array}{l}\text { Control of vehicle speed } \\
\text { to stop at reversing point, } \\
\text { steering, gear change. }\end{array}$ \\
\hline 9 & Towards bank & $\begin{array}{l}\text { Control of vehicle speed, steering in a } \\
\text { V-pattern, lowering bucket to the ground. }\end{array}$ \\
\hline 10 & $\begin{array}{l}\text { Speed reduction } \\
\text { before the bank }\end{array}$ & $\begin{array}{l}\text { Control of vehicle speed, } \\
\text { use the momentum to dig the bucket } \\
\text { into the pile. }\end{array}$ \\
\hline
\end{tabular}

To improve the efficiency of wheel loader operation, smart improvements in wheel loader control strategies and design of operator assisting systems are beneficial. OC analysis of wheel loader operation, is able to highlight the potentials for improvement of operator behavior in wheel loader steering, load 
lifting and engine control during the SLC. The solution trajectories obtained from optimal control also constitutes a first step towards autonomy, since this gives one solution to the path planning problem. As it is desired to remove humanistic errors in wheel loader control, and thanks to the developments in control capabilities, research on autonomous loading operations is growing rapidly, for some examples see [1], [41], [64] and [75].

Many parameters contribute to the efficient operation of a wheel loader and [20] has performed experiments to identify these parameters. According to the measurements in [20], after the wheel loader bucket is filled, load lifting and vehicle traction are the major power consuming subsystems of a wheel loader. The control of steering subsystem is also important as it affects the trajectory length and consequently the required traction power and SLC duration. Some workspace parameters such as the angle at which the wheel loader meets the load receiver for unloading the bucket can also affect the trajectory and are therefore important for an efficient operation. Wheel loader operation in SLC is analyzed with respect to various parameters and the complete details about the analysis results and methodology are presented in Papers 1-6.

\subsection{Gear shift control in heavy duty powertrain}

The second group of $\mathrm{OC}$ applications considered in this dissertation, Papers 7-9, are focused on the modeling and $\mathrm{OC}$ of powertrain transients during gear shifts in AT and AMT systems. Extensive research has been carried out on gear shift control and control objectives, see [26], [30], [31], [51], [74], and it is shown that the faster and smoother gear shifts are vital for better ride quality and longer life of transmission components. Moreover, AT and AMT system control is important for the improvement of fuel consumption and reduction of emissions [69].

AT systems with planetary gearsets are used in different types of vehicles, see [47] and [83], as well as heavy duty applications such as [79]. In such transmission systems, a gear ratio is obtained via actuation of oil immersed brakes and clutches, referred to as shift elements, inside the transmission housing such that the components of the gearsets are linked together according to a predefined arrangement. Shifting to another gear is performed by disengaging some shift elements and engaging some new ones such that a new arrangement between gearset components is achieved. Meanwhile, the components being coupled or decoupled have various rotational speeds and inertias. Therefore, the disengagement of off-going and engagement of in-coming shift elements need to be carefully supervised to ensure a fast gearshift. Proper control is also important to avoid oscillations in the driveline which can have severe destructive effects on the transmission and other driveline components, and also deteriorate the passenger comfort.

The control study of torque phase transients during an AT gear shift can be carried out with focus on the hydraulic shift element actuation system as in [24], [51] and [76]. It is also common as in [29] and [38] to consider the hydraulic actuation pressures as control inputs and focus on the dynamics of the 
powertrain and transmission components during the gear shift. In Paper 7, the second approach is used and OC analysis of the gear shift for a nine speed AT system is enabled by developing physics based model of the transmission and driveline rotational dynamics during a gear shift. The presented methodology is reusable for OC analysis of various gear shifts for the hauler in [79].

AMT systems are popular in commercial vehicle since they offer improved shift quality and drive comfort while reducing the gear shift duration and fuel consumption [49]. Moreover, according to [49] as they are derived from the manual transmission systems, development and production of AMT systems have lower cost compared to the AT systems. Generally, the major difference between manual and AMT systems is that in an AMT, the clutch and gearbox are equipped with electro mechanical or electro hydraulic actuators driven by a control unit. The overall goal of the control unit as in the AT case is to improve the shift quality by shortening the gear shift duration and driveline oscillations. However, shortening the duration of gear shift is more critical for AMT systems because during the gear shift, zero tractive torque is transferred to the wheels which causes vehicle speed deceleration and is undesirable especially for heavier vehicles. Many researches have been carried out for modeling and control of AMT systems. From detailed vibrational and finite element analysis of the transmission shaft including clutch nonlinearities and backlash effects in [16], to multi-body driveline modeling approach in [14] and [60]. Clutch models for the slipping and locked modes of the clutch operation and the thermal effect on the transmitted torque are presented in [52]. The control of AMT gear shift is well studied in [46], [61] and [86].

Engine controlled gear shifts in an AMT system similar to [61] but including an assisting electric power source in the powertrain are studied in Papers 8-9. To analyze the OC transient during the gear shifts, first a model is developed and then $\mathrm{OC}$ problems are formulated and solved showing the potentials for reduction of fuel consumption and driveline oscillations. Chapter 2 follows up on this and presents the important issues in modeling and $\mathrm{OC}$ of such gear shifts.

Although developing continuous and control friendly models are a key requirement for $\mathrm{OC}$ analysis, it is important to have a proper objective function formulation in OC problems. Paper 10 and briefly the last section of chapter 2 present the effects of objective function formulation on the obtained optimal trajectories when solving $\mathrm{OC}$ problems.

\subsection{Summary and contributions of the papers included in the thesis}

The main contributions of Papers 1-10 are summarized below. The first author in each paper has the largest contribution in the study, implementation and presentation of the results. 


\section{Paper 1}

"Modeling and optimal control of a wheel loader in the lift-transport section of the short loading cycle." Vaheed Nezhadali, Lars Eriksson, and Anders Fröberg. 7th IFAC Symposium on Advances in Automotive Control. Tokyo, Japan, 2013.

The main contribution of this paper is a wheel loader model which can be used in $\mathrm{OC}$ problem formulation. A second contribution, is that it is shown how multi-phase OC problems can be formulated and solved for obtaining efficient wheel loader transients in presence of discontinuous control inputs such as gearbox ratios. Solving OC problems, the trade-off between shortest time and lowest fuel consumption for wheel loader operation is calculated. The paper also includes an analysis of the effects of torque converter stiffness on fuel-time trade-off. The sensitivity of $\mathrm{OC}$ transients with respect to the path constraints in the lifting subsystem is also investigated.

\section{Paper 2}

"Optimal control of wheel loader operation in the short loading cycle using two braking alternatives."

Vaheed Nezhadali and Lars Eriksson.

The 9th IEEE Vehicle Power and Propulsion Conference. Beijing, China, 2013.

This paper is a continuation of wheel loader OC analysis using the model developed in Paper 1. The main contribution in this paper is showing the effects on fuel consumption when using torque converter and engine torque for wheel loader braking instead of using usual mechanical brakes. Fuel efficient wheel loader transients and also the trade-off between minimum time and minimum fuel operations are calculated and presented showing the higher fuel consumption when the torque converter is used for braking.

\section{Paper 3}

"Optimal lifting and path profiles for a wheel loader considering engine and turbo limitations."

Vaheed Nezhadali and Lars Eriksson.

Volume 455 of Lecture Notes in Control and Information Sciences. pp. 301-324. Springer International Publishing.

The paper is an extension of Paper 1 where the main contributions is the improvement of wheel loader model. The new model includes turbocharger dynamics in the mean value engine model and also a model for the steering system dynamics. Using the extended model and a numerical OC tool, the minimum time and minimum fuel transients and power distribution between different wheel loader sub-systems are calculated and presented. Another important contribution is the calculation of optimal wheel loader trajectories in the short loading cycle for various load receiver positions. 


\section{Paper 4}

"Turbocharger dynamics influence on optimal control of diesel engine powered systems."

Vaheed Nezhadali, Martin Sivertsson, and Lars Eriksson.

SAE International Journal of Engines, DOI: 10.4271/2014-01-0290.

This paper contributes with an analysis of effects of including turbocharger dynamics in diesel powered systems. A qualitative and quantitative comparison is presented for two applications where the authors have contributed with the wheel loader application. It is shown that neglecting the turbocharger dynamics results in underestimations when calculating the required time and fuel for wheel loader operation.

\section{Paper 5}

"Wheel loader optimal transients in the short loading cycle." Vaheed Nezhadali and Lars Eriksson.

The 19th IFAC World Congress. Cape Town, South Africa, 2014.

This paper is an extension of Paper 3. The main contribution here is that the complete trajectory in the short loading cycle is optimized compared to the previous papers where only the lift-transport section of the loading cycle was in focus. The sensitivity of the wheel loader transients, fuel consumption, cycle duration and trajectory with respect to unloading point orientations of the wheel loader are calculated and presented.

\section{Paper 6}

"Wheel loader operation - optimal control compared to real drive experience."

Vaheed Nezhadali, Bobbie Frank, and Lars Eriksson.

Control Engineering Practice, DOI:10.1016/j.conengprac.2015.12.015.

The main contribution of this paper is that the results from OC analysis are compared with the measurements from a real world wheel loader operation with the aim to highlight the potentials for improvement of operation productivity. The wheel loader model in Paper 5 is fine tuned and its fuel consumption calculation is validated against measurements. Using the validated model, OC problems are formulated, solved and the results are compared against the measured trajectories and fuel consumptions. 


\section{Paper 7}

"A framework for modeling and optimal control of automatic transmission systems."

Vaheed Nezhadali and Lars Eriksson.

4th IFAC Workshop on Engine and Powertrain Control, Simulation and Modeling. Columbus, USA, 2015.

The main contribution of this paper is the presentation of a methodology for modeling and control of actuators in automatic transmissions with planetary gearboxes. The presented model is reusable for various gear shift cases and is continuous in the operating range of the transmission system which makes it proper for OC problem formulation. This is shown by solving OC problems to calculate the trade-off between gear shift time and wheel speed oscillations.

\section{Paper 8}

"Optimal control of a diesel-electric powertrain during an up-shift." Vaheed Nezhadali and Lars Eriksson.

SAE 2016 World Congress 6 Exhibition, paper number 2016-01-1237. Detroit, USA, 2016.

The contribution in this paper is a methodology for modeling and OC analysis of complex powertrain configurations. A model is developed for a heavy duty powertrain using a validated diesel-electric model and a coupleddecoupled transmission assumption during a clutch free gear shift. OC analysis for minimization of gear shift time and transmission shaft oscillations is performed and results are presented.

\section{Paper 9}

"Optimal control of gear shift in a diesel-electric powertrain with backlash." Vaheed Nezhadali and Lars Eriksson.

8th IFAC Symposium on Advances in Automotive Control. Kolmården, Sweden, 2016.

This paper is an extension of Paper 8. The powertrain model is extended by including a backlash in the driveline which is a strong nonlinearity. The main contribution is to introduce a new smoothing technique in order to describe the discontinuous backlash dynamics using a continuous switching function during all phases of an engine controlled gear shift. Using the powertrain model, the paper contributes with a discussion about how objective functions of OC problems should be formulated to obtain fuel-time-jerk efficient gear shift transients. 


\section{Paper 10}

"Analysis of optimal diesel-electric powertrain transients during a tip-in maneuver."

Vaheed Nezhadali and Lars Eriksson.

9th Eurosim Congress on Modelling and Simulation. Oulu, Finland, 2016.

This paper contributes with a discussion and analysis of objective function formulations in $\mathrm{OC}$ analyses. A diesel-electric powertrain corresponding to a hybrid bus is used and OCs for acceleration from 10 to $15 \mathrm{~km} / \mathrm{h}$ are calculated. The analysis is performed for minimization of time, driveline jerk, and energy consumption. The trade-off between these criteria are calculated meanwhile a weighted sum of diesel and electric energy is used to define the energy cost function in the problem formulation. The analysis is extended by recalculating the transients for various weights in the energy cost formulation and different road slopes corresponding to various loads. It is shown that with the same model, including different aspects of the system properties in the objective function formulation can greatly affect optimal transients and this should be considered in $\mathrm{OC}$ analysis of powertrain systems.

\section{Other publications by the author}

The publications in which the author has participated but are not included in the dissertation are as follows:

- "Compressor flow extrapolation and library design for the Modelica vehicle propulsion library - VehProLib."

Lars Eriksson, Vaheed Nezhadali, and Conny Andersson.

SAE 2016 World Congress \& Exhibition. SAE paper 2016-01-1037. Detroit, United States.

- "Parallel multiple-shooting and collocation optimization with OpenModelica".

Bernhard Bachmann, Lennart Ochel, Vitalij Ruge, Mahder Gebremedhin, Peter Fritzson, Vaheed Nezhadali, Lars Eriksson, and Martin Sivertsson. 9th International Modelica Conference. Munich, Germany, 2012. 


\section{On modeling and optimal control of heady duty powertrains}

This chapter gives a short introduction to the modeling and Optimal Control (OC) of the studied heavy duty powertrains. First the models and OC problem formulations used for wheel loader operation analyses in Papers 1-6 are briefly presented. Then, the system models and problem formulations related to Papers 7-10, which are about gear shift and driveline control, are presented. Finally, the chapter is concluded by some remarks about the choice of OC problem solvers in Papers 1-10, and the importance of objective function formulation for OC analysis of systems comprised of several subsystems. Meanwhile, the previous research in the field and their relation to this dissertation are reviewed in every section.

\subsection{Wheel loader modeling and control}

Several studies are performed on modeling, simulation and optimization of the different phenomena during typical wheel loader operation. Digging forces during the bucket filling process are studied in [18] while in [15], [19] and [58] only the lift system hydraulics and the linkage dynamics are in focus. The effects of wheel loader operator skills on the Short Loading Cycle (SLC) efficiency are studied in [23]. Several studies are available concentrating only on wheel loader trajectory planning with [21], [55], [67], [65] and [66] as some examples. In [42] a model is presented for the pile shape while in [63] and [68] the trajectory planning considering the cycle to cycle deformation of the gravel pile is presented. Research on the optimization of diesel engine transient operations also attracts several researchers such as [84], [5] and [4]. During wheel loader operation almost all different wheel loader subsystems are employed simultaneously while research on modeling and $\mathrm{OC}$ for the total system during loading operation is rare. 
Table 2.1: Summary of wheel loader model features used in Papers 1-6.

\begin{tabular}{lllllll}
\hline Paper & 1 & 2 & 3 & 4 & 5 & 6 \\
\hline Number of states & 5 & 4 & 9 & 9 & 9 & 9 \\
Number of controls & 3 & 3 & 4 & 4 & 4 & 4 \\
Trajectory planning included & - & - & $\checkmark$ & $\checkmark$ & $\checkmark$ & $\checkmark$ \\
Turbocharger dynamics included & - & - & $\checkmark$ & $\checkmark$ & $\checkmark$ & $\checkmark$ \\
Hydraulic lift pressure as control & - & - & - & - & - & $\checkmark$ \\
Compared with measured data & - & - & - & - & - & $\checkmark$ \\
\hline
\end{tabular}

In this dissertation, all major power producer and consumers are included in the models and the analyses. To enable this, models describing the dynamics of the wheel loader components contributing to both SLC duration and fuel consumption are required. It is important to accurately describe the component dynamics with minimum number of states and control inputs in order to facilitate OC analysis with available techniques. Also, the dynamics of all subsystems and components should remain continuous during the whole range of wheel loader operation. For this, the wheel loader dynamics are initially described with simpler models, Paper 1, and in the following papers more components and subsystems are added as shown in Table 2.1. Wheel loader modeling culminates in the model presented in Paper 6 where a comparison is made between measurements from real wheel loader operation and OC results using the developed model for a L220G VOLVO wheel loader, [81].

\subsubsection{Wheel loader models in Papers 1-6}

Figure 2.1 illustrates an overview of the complete wheel loader model in Paper 6 showing the interdependencies between various subsystems. The complete wheel loader model has four control inputs which are injected fuel mass per combustion cycle of the diesel engine $\left(u_{f}\right)$, hydraulic pressure in the lifting system $\left(u_{p}\right)$, rate of change in steering angle $\left(u_{s}\right)$ and a resistive force at wheels $\left(u_{b}\right)$ representing the braking force from mechanical service brakes. The transients of various subsystems are described by differential equations for nine state variables which are engine speed $\left(\omega_{i c e}\right)$, engine intake manifold pressure $\left(p_{i m}\right)$, angular position and velocity of the lift boom $(\theta, \omega)$, vehicle speed $(V)$, vehicle position in $2-\mathrm{D}$ plane $(X, Y)$, steering angle $(\delta)$ and the heading angle of the vehicle $(\beta)$.

Detailed models suitable for control purposes and describing diesel engine transients are available, see [85] and [35]. However, considering the number of subsystems included in the wheel loader model and to reduce the size of the model, only engine speed and intake manifold pressure states are used. In Paper 4 it is shown that including the intake manifold pressure dynamics together with the smoke limit constraint representing the turbo lag effect in the diesel engine model, is necessary for the correct estimation of fuel consumption and operation duration.

It is common to use torque converters in wheel loader powertrains [80], [48], [39], [36], [34], [13]. Considering the environments that wheel loaders operate in, high wheel slip conditions are common. During these periods, it is important 


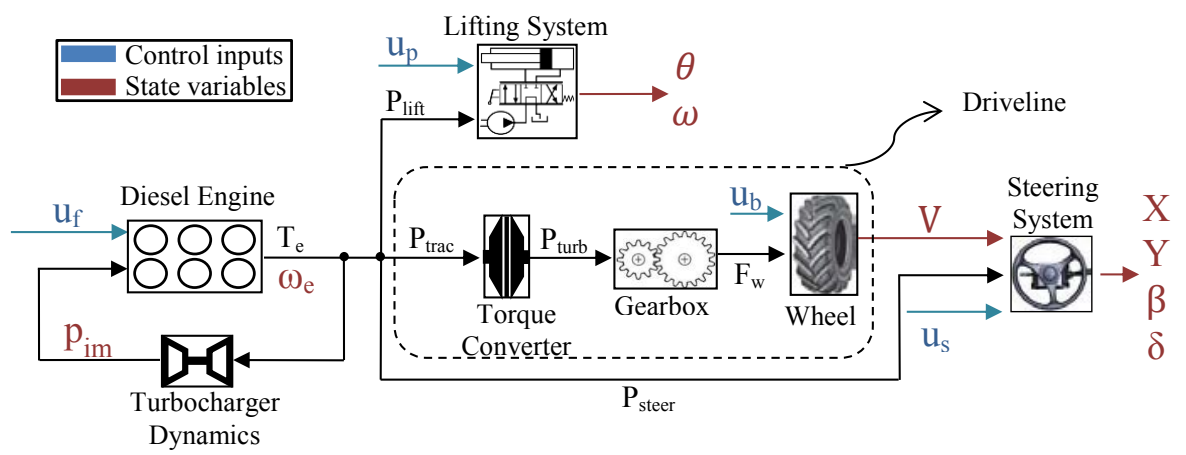

Figure 2.1: The structure of complete wheel loader model and its comprising subsystems, states and controls according to [53].

to decouple the disturbances in the vehicle speed and wheel torque from the engine. Using a torque converter, the engine and wheels are hydraulically coupled together having better disturbance damping characteristics compared to a mechanical coupling. Having a torque converter in the drive train also brings the benefit that with no clutching mechanism in the system, vehicle speed can go to zero without stalling the engine. According to [54], this is particularly important during the bucket filling phase of the wheel loader operation. However, the high losses associated with the torque converter operation make it crucial to have efficient powertrain control strategies and this is more elaborated in Papers 1-2.

Same as a diesel engine, detailed models describing the dynamics of torque converter components are available with examples available in [33] and [40]. However, in control oriented modeling it is common to neglect the internal dynamics of the torque converter and represent the component by it characteristics curves, see [28] for an example. In some of the wheel loader applications studied in this dissertation, such as Paper 2, it is desired to have a torque converter model able to transfer torque from the engine to the wheels and also in the reverse direction. For this, similar approach as in [27] and [28] with minor modifications in order to obtain continuous and usable models over the complete range of the speed ratios over torque converter are used.

In the lift subsystem models, the main goal is to obtain efficient lifting profiles during the loading operation while accounting for the required power from the diesel engine. The focus is therefore put on the kinematics and according to the geometry of the boom and lift cylinders, the lifting force and acceleration are calculated proportional to the hydraulic pressure $\left(u_{p}\right)$ in the lift cylinders. Moreover, assuming a constant efficiency for the lifting pumps and using the properties in [81], the required power for lifting is calculated.

Steering system is modeled using vehicle kinematics for an articulated configuration with equidistant axles from the articulation joint. The required power for steering is much less than the power required for lifting and vehicle trac- 


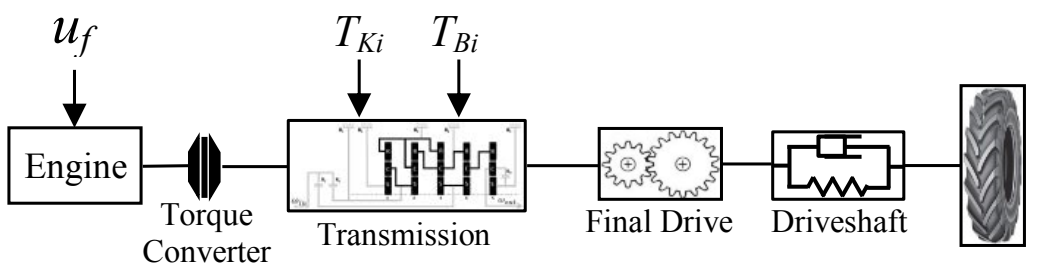

Figure 2.2: The AT powertrain configuration used for gear shift and driveline control analysis in Paper 7.

tion [20]. Therefore it is modeled as a simple quadratic function proportional to the steering angular velocity as presented in Paper 3. The steering model enable calculation of optimal wheel loader trajectory while allowing to define a constraint on the maximum turning radius of the vehicle according to the information in [81].

\subsection{Modeling for AT gear shift control}

The powertrain configuration used for OC of AT gear shift transients is presented in Figure 2.2. In the AT powertrain model presented in Paper 7, to capture the driveline and transmission oscillations during the gear shift, the rotational speed of the engine and transmission components, and wheel speed are chosen as state variable describing the powertrain rotational dynamics. The only flexibility in the system is considered to be in the driveshaft where the driveshaft deflection dynamics are described using damping and stiffness coefficients according to [61]. The control inputs are injected fuel mass per combustion cycle $\left(u_{f}\right)$ and the actuation torques $\left(T_{k i}, T_{B i}\right)$ exerted on the planetary gearset components by the clutches and brakes inside the transmission.

Black box models represent the torque converter characteristic curves in the model as in the wheel loader case. Different approaches are used to describe the rotational dynamics of the planetary gearset components. Lever analogy [8] is widely used over the past 35 years for the analysis and visualization of the AT gear shift systems as in [50] and [70]. However, illustration of torques using the lever analogy method for AT systems with more number of planetary gearsets, we had 5 of them in Paper 7, becomes cumbersome to use and thus less efficient. However, considering only the kinematic of the transmission system and using Newton's second law, it is possible to calculate all torques applied on the different planetary gearset components in order to describe the rotational dynamics. This approach, referred to as the matrix method in [7], is more efficient for the analysis of larger and more complex transmissions systems and is used in Paper 7 as well as [77]. 


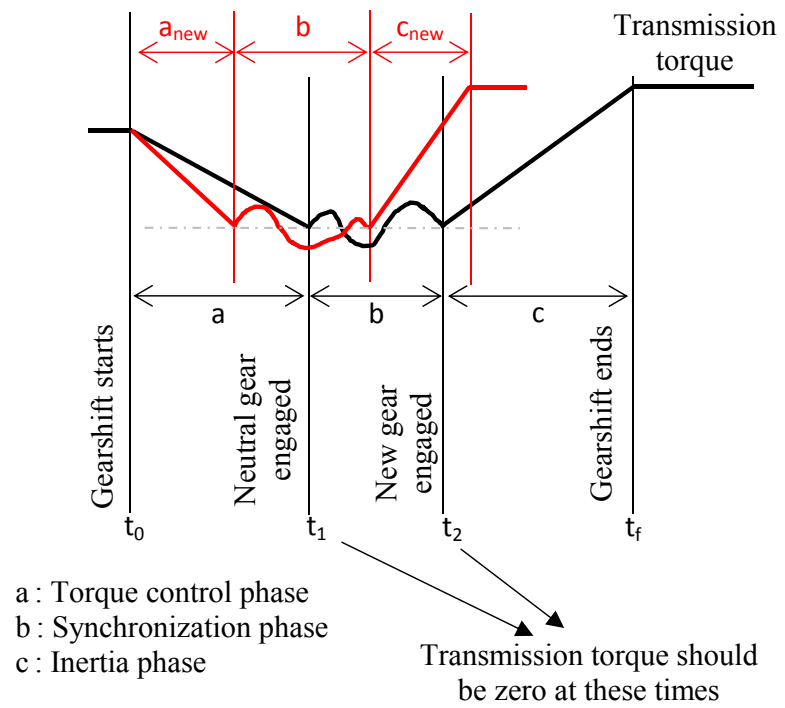

Figure 2.3: Schematic illustration of the transmission torque during an engine controlled gearshift in an AMT system. Black curves show the torque from a conventional diesel powertrain and red curves show the anticipated torque transients using a diesel-electric power source.

\subsection{Modeling for AMT gear shift control}

In AMT systems studied in Papers 8-9, the gear shift transients are described by three consecutive phases namely torque phase, synchronization phase and inertia phase. Figure 2.3 schematically shows the transmission torque transients in the three phases of a conventional engine controlled gearshift versus the transients expected when an assisting electric power source is available in the powertrain. The torque phase starts after the driver commands a gear shift. The engine torque control is then activated in order to smoothly reach zero transferred torque in the transmission. This facilitates slip-free actuation of the electrically controlled clutch for decoupling the engine from the gearbox. During the synchronization phase, a new gear is put in place inside the gearbox while engine speed is synchronized to match the new gear ratio; meanwhile the engine torque is controlled to zero level to enable the slip-free re-engagement of the engine and gearbox at the end of this phase. In the third phase, the engine torque and rotational speeds of the inertias in the powertrain are increased such that the desired wheel speed is achieved at the end of the gear shift.

Figure 2.4 shows the powertrain configurations in the models used for the study of the AMT shift control. In Papers 8-10, a validated diesel-electric model from [71] as the power source in the powertrain is used. The control input to the model are mass of injected fuel per combustion cycle $\left(u_{f}\right)$, turbocharger wastegate valve position $\left(u_{w g}\right)$ and the electric power from/to the generator/motor 


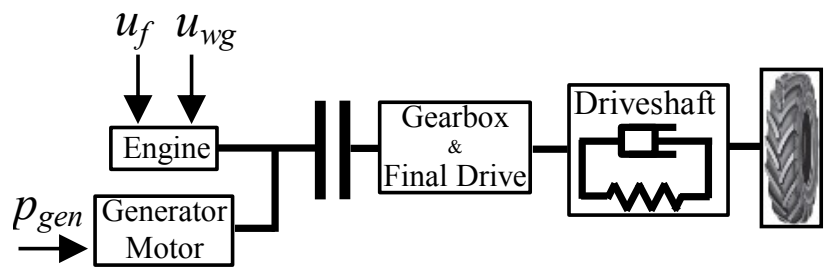

Figure 2.4: The AMT powertrain structure used in gear shift and driveline control analyses, Papers 8-10.

$\left(p_{g e n}\right)$. The rotational dynamics of the driveline are described by engine speed, transmission output shaft speed and wheel speed according to the decoupled modeling approach suggested in [60]. The driveline flexibilities are all lumped together and described by the driveshaft stiffness and damping coefficients.

According to [44], a backlash angle in the range of 20-40 crankshaft angle degrees can be encountered in vehicular drivelines. Therefore, to have a more realistic representation of the driveline dynamics, the powertrain model of Paper 8 is extended in Paper 9 by addition of backlash transients into the system. [57] presents physical backlash models and [43] has performed a survey on control of automotive powertrains with backlash while methods for backlash estimation and open-loop control during backlash traverse are suggested in [44] and [45]. However, describing backlash nonlinearities with a single continuous dynamic model for both traverse and contact modes in a reusable manner for all three phases of the AMT gear shift is less trivial. For this, as presented in Paper 9, a continuous and differentiable switching function is introduced for calculation of the backlash transients at different backlash modes. OC problems are then formulated and solved using the powertrain model of Paper 8 but with an additional state for the backlash traverse angle. It is shown that the suggested methodology for backlash definition can be used for the AMT gear shift control of systems with backlash.

\subsection{Solving optimal control problems}

\subsubsection{Optimal control solvers}

Different methods and approaches are available for solving OC problems. However, the size of models and number of states and controls, play an important role when choosing a solution method. Meanwhile classical methods such as Pontryagin's Maximum Principle [62] or Dynamic Programming [9] are suitable for problems with smaller state space and fewer nonlinearities, direct numerical optimal control (NOC) methods, see [17] and [56] for an overview, are almost the only choice when it comes to larger problems with severe nonlinearities. The idea in direct method approaches is that the OC problem is first translated into a nonlinear problem (NLP) using various discretization methods. The NLP is then solved by dedicated solvers such as IPOPT [82] in CasADi framework [3] 
or SNOPT [25] in PROPT [78], ACADO [32] and GPOPS [59].

Considering the size and complexities of the models and $\mathrm{OC}$ problems studied in this dissertation, the direct methods are the natural choice among all available options. In Papers 1-6 PROPT is used which has the advantage that large OC problems in multiple phases can be simply defined. However, there is less freedom for choosing the discretization method and the user is limited to the tool syntaxes for the definition of system models. As the research has progressed and we have gained more knowledge about the discretization techniques such as direct multiple shooting and direct collocation, CasADi is used in Papers 7-10 for formulating and solving OC problems. The main advantage of this tool is that more complex problems can be formulated and solved with it since the user has more freedom in defining the system model and implementing the discretization methods of his choice. However, the discretization complexities and coding requirements increase the time that is needed to implement the complete OC problem definition in CasADi.

From a user's perspective PROPT is a useful tool for getting started and capable of solving problems of industrially relevant size. But in the project, we reached the limit and found needs to go beyond the capabilities of PROPT, however, the thesis results would not have been possible without this progression.

\subsubsection{Practical notes about OC solutions}

Solving different types of OC problems it is common to come up with control or state trajectories which are noisy or oscillatory and seem far from the anticipations during a real operation. The oscillations can have various frequencies and also various origins. They may be the results of physical phenomena existing in real world which have not been realized earlier or can be the artifact of problem discretization or modeling choices. In [72] and [73], examples are presented where oscillatory engine controls using a mean value diesel engine model are proven to be actually more fuel efficient. Paper 1 in the dissertation presents an example where oscillations are caused by the modeling and discretization choices.

Another type of unexpected control or state trajectories which can be highly oscillatory or of bang-bang type are the result of choices made for objective function formulation of OC problems. In Papers 1-9 such situations are avoided by calculating the trade-off between contradicting objectives and showing the differences in the transients between the first points on the Pareto front and where a compromise between objectives exist. Paper 10 is dedicated to the study of such conditions while calculating optimal powertrain controls for smooth and time efficient tip-in transients of a hybrid city bus.

Figure 2.5 shows a schematic description of the arising problem with imaginary optimal state and control trajectories when solving for two different objective function formulations. The system to be optimized is assumed to be comprised of two subsystems with feasible regions as shown in the figure. Two contradicting objective functions $\left(f_{1}\right)$ and $\left(f_{2}\right)$ which can correspond to fuel consumption and time, respectively, are considered. As it is shown, when the optimization is aimed at minimization of only one of the objectives, the control trajectory aims at 


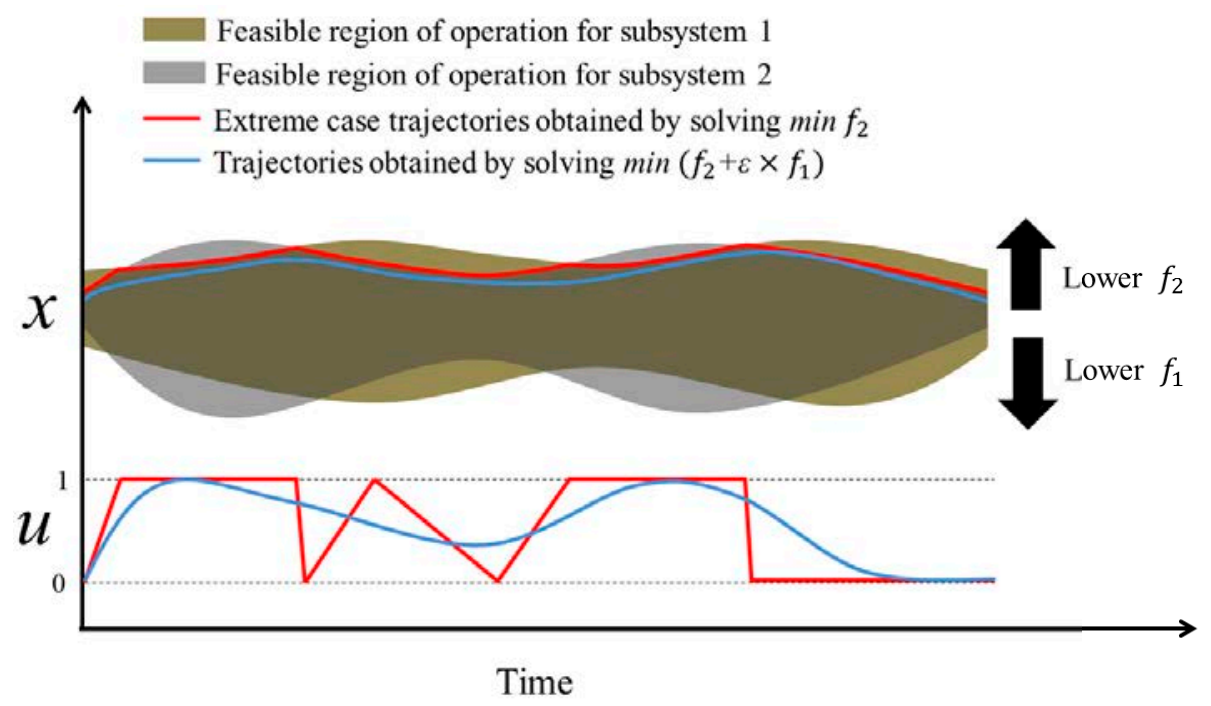

Figure 2.5: A schematic illustration describing the effects of objective function formulation on system transients obtained from optimal control.

pushing the state transients toward the boundaries of the common feasible region of the two subsystems. However, commonly the bottle neck of the system model accuracy lies on its boundaries and therefore the control signals corresponding to such operating regions may look unrealistic. But if a small representation of the other objective $\left(\epsilon \times f_{1}\right)$ is added to the optimization objective, while the state trajectory remains close to the first case results, the control trajectory becomes much smoother and which is more insightful for control design.

Therefore, when formulating and solving OC problems, while it is important to have proper models and discretization schemes, formulation of objective function should also be carefully decided. This becomes even more important when systems are comprised of many subsystems with various efficient regions during the operations. 


\section{References}

[1] B. Alshaer, T. Darabseh, and M. Alhanouti. Path planning, modeling and simulation of an autonomous articulated heavy construction machine performing a loading cycle. In Applied Mathematical Modelling, volume $37-7$, pages $5315-5325,2013$.

[2] M. Ammann, N. P. Fekete, L. Guzzella, and A. Glattfelder. Model-based control of the vgt and egr in a turbocharged common-rail diesel engine: theory and passenger car implementation. SAE transactions, 112(3):527-538, 2003.

[3] J. Andersson. A General-Purpose Software Framework for Dynamic Optimization. PhD thesis, Arenberg Doctoral School, KU Leuven, Department of Electrical Engineering (ESAT/SCD) and Optimization in Engineering Center, Kasteelpark Arenberg 10, 3001-Heverlee, Belgium, October 2013.

[4] J. Asprion, O. Chinellato, and L. Guzzella. Efficient solution of the dieselengine optimal control problem by time-domain decomposition. Control Engineering Practice, 30:34-44, 2014.

[5] J. Asprion, O. Chinellato, and L. Guzzella. Optimal control of diesel engines: Numerical methods, applications, and experimental validation. Mathematical Problems in Engineering, 2014.

[6] K. J. Åström and B. Wittenmark. Adaptive control. Courier Corporation, 2013.

[7] S. Bai, J. Maguire, and H. Peng. Dynamic Analysis and Control System Design of Automatic Transmissions. SAE International, 2013. 
[8] H. L. Benford and M. B. Leising. The lever analogy: A new tool in transmission analysis. SAE Technical Paper 1981-02-01, 1981.

[9] D. P. Bertsekas. Dynamic programming and optimal control, volume 1. Athena Scientific Belmont, MA, 1995.

[10] Betänkande av utredningen om fossilfri fordonstrafik. Fossilfrihet på väg del 1. STATENS OFFENTLIGA UTREDNINGAR, SOU 2013:84, 2013.

[11] C. Brosilow and B. Joseph. Techniques of model-based control. Prentice Hall Professional, 2002.

[12] E. F. Camacho and C. B. Alba. Model predictive control. Springer Science \& Business Media, 2013.

[13] Caterpillar. Products: Wheel Loaders, "http://www.cat.com/en_US/ products/new/equipment/wheel-loaders.html", 2016.

[14] D. Centea, H. Rahnejat, and M. Menday. Non-linear multi-body dynamic analysis for the study of clutch torsional vibrations (judder). Applied Mathematical Modelling, 25(3):177-192, 2001.

[15] M. Cobo, R. Ingram, and S. Cetinkunt. Modeling, identification, and real-time control of bucket hydraulic system for a wheel type loader earth moving equipment. Mechatronics, 8(8):863 - 885, 1998.

[16] P. Couderc, J. Callenaere, J. D. Hagopian, G. Ferraris, A. Kassai, Y. Borjesson, L. Verdillon, and S. Gaimard. Vehicle driveline dynamic behaviour: experimentation and simulation. Journal of sound and vibration, 218(1):133157, 1998.

[17] M. Diehl. Numerical optimal control drafts. 2011.

[18] A. Ericsson and J. Slättengren. A model for predicting digging forces when working in gravel or other granulated material. In 15th European ADAMS Users' Conference, pages 15-17. Citeseer, 2000.

[19] R. Fales, E. Spencer, K. Chipperfield, F. Wagner, and A. Kelkar. Modeling and control of a wheel loader with a human-in-the-loop assessment using virtual reality. Journal of dynamic systems, measurement, and control, 127(3):415-423, 2005.

[20] R. Filla. Quantifying Operability of Working Machines. PhD thesis, Linköping UniversityLinköping University, Fluid and Mechatronic Systems, The Institute of Technology, 2011.

[21] R. Filla. Optimizing the trajectory of a wheel loader working in short loading cycles. In The 13th Scandinavian international conference on fluid power, SICFP2013, pages 3-5, 2013.

[22] C. Folkerts, K. Dudek, G. Matthews, W. Orrell, and M. Livshiz. Powertrain control system, Aug. 2002. 
[23] B. Frank, L. Skogh, and M. Alaküla. On wheel loader fuel efficiency difference due to operator behaviour distribution. In 2nd International Commercial Vehicle Technology Symposium, CVT, 2012.

[24] B. Gao, H. Chen, H. Zhao, and K. Sanada. A reduced-order nonlinear clutch pressure observer for automatic transmission. Control Systems Technology, IEEE Transactions on, 18(2):446-453, 2010.

[25] P. E. Gill, W. Murray, and M. A. Saunders. An sqp algorithm for large-scale constrained optimization. SIAM Journal on Optimization, pages 979-1006, 1997.

[26] M. Goetz, M. Levesley, and D. Crolla. Dynamics and control of gearshifts on twin-clutch transmissions. Proceedings of the institution of mechanical engineers, Part D: Journal of Automobile Engineering, 219(8):951-963, 2005.

[27] L. Guzzella and A. Sciarretta. Vehicle Propulsion Systems, Introduction to Modeling and Optimization. Springer, 2007.

[28] A. Haj-Fraj and F. Pfeiffer. Optimal control of gear shift operations in automatic transmissions. Journal of the Franklin Institute, 338(2):371-390, 2001.

[29] A. Haj-Fraj and F. Pfeiffer. A model based approach for the optimisation of gearshifting in automatic transmissions. International journal of vehicle design, 28(1):171-188, 2002.

[30] W. Han and S. Yi. A study of shift control using the clutch pressure pattern in automatic transmission. Proceedings of the Institution of Mechanical Engineers, Part D: Journal of Automobile Engineering, 217(4):289-298, 2003.

[31] K. Horste. Objective measurement of automatic transmission shift feel using vibration dose value. SAE Technical Paper 1995-05-01, 1995.

[32] B. Houska, H. Ferreau, and M. Diehl. ACADO toolkit - an open source framework for automatic control and dynamic optimization. Optimal Control Applications \& Methods, 32(3):298-312, 2011.

[33] D. Hrovat and W. E. Tobler. Bond graph modeling and computer simulation of automotive torque converters. Journal of the Franklin Institute, 319:93$114,1985$.

[34] Hyundai Heavy Industries. Products: Wheel Loaders, "http://constructionequipment.hyundai.eu/en/products/ wheeled-loaders-loaders", 2016.

[35] M. Kao and J. J. Moskwa. Turbocharged diesel engine modeling for nonlinear engine control and state estimation. Journal of dynamic systems, measurement, and control, 117(1):20-30, 1995. 
[36] Kawasaki Construction Machinery. Products: Wheel Loaders, "http:// wWw. kcmcorp.com/products/wheel-loaders/90Z7T4F", 2016.

[37] U. Kiencke and L. Nielsen. Automotive control systems: for engine, driveline, and vehicle, 2000.

[38] D. Kim, K. Yang, K. Hong, J. Hahn, and K. Lee. Smooth shift control of automatic transmissions using a robust adaptive scheme with intelligent supervision. International journal of vehicle design, 32(3):250-272, 2003.

[39] Komatsu. Products: Wheel Loaders, "http://www.komatsuamerica.com/ equipment/wheelloaders", 2016.

[40] A. J. Kotwicki. Dynamic models for torque converter equipped vehicles. SAE Technical Paper 1982-02-01, 1982.

[41] N. Koyachi and S. Sarata. Unmanned loading operation by autonomous wheel loader. In Proceedings of the ICROS-SICE International Joint Conference, pages 2221-2225, 2009.

[42] N. Koyachi, S. Sarata, and H. Ishimoto. Pile shape measuring in excavating and loading by wheel loader. In Mine Planning and Equipment Selection, pages 921-929. Springer, 2014.

[43] A. Lagerberg. A literature survey on control of automotive powertrains with backlash. Chalmers tekniska högsk., 2001.

[44] A. Lagerberg. Control and estimation of automotive powertrains with backlash. PhD thesis, Chalmers University of Technology, 2004.

[45] A. Lagerberg. Open-loop optimal control of a backlash travers. Chalmers tekniska högskola, 2004.

[46] H. Lee, S. Sul, H. Cho, and J. Lee. Advanced gear-shifting and clutching strategy for a parallel-hybrid vehicle. Industry Applications Magazine, IEEE, $6(6): 26-32,2000$.

[47] M. Link, B. Vob, E. Eggert, and R. Nasdal. The automated shift transmission (ast) - possibilities and limits in production-type vehicles. SAE Technical Paper 2001-01-0881, 2001.

[48] LiuGong. Products: Wheel Loaders, "http://www.liugong.com/en_me/ products/loader.htm", 2016.

[49] G. Lucente, M. Montanari, and C. Rossi. Modelling of an automated manual transmission system. Mechatronics, 17(2):73-91, 2007.

[50] Y. Minagawa, T. Oshidari, K. Kargar, and Y. Pichon. Shift control device for hybrid vehicle, Nov. 16 2004. US Patent 6,819,985.

[51] T. Minowa, T. Ochi, H. Kuroiwa, and K. Liu. Smooth gear shift control technology for clutch-to-clutch shifting. SAE Technical Paper 1999-01-1054, 1999 . 
[52] A. Myklebust and L. Eriksson. Modeling, observability, and estimation of thermal effects and aging on transmitted torque in a heavy duty truck with a dry clutch. IEEE/ASME Transactions on Mechatronics, $\operatorname{PP}(99): 1-12$, February 2014.

[53] V. Nezhadali, B. Frank, and L. Eriksson. Wheel loader operation-optimal control compared to real drive experience. Control Engineering Practice, $48: 1-9,2016$.

[54] T. Nilsson. Optimal Predictive Control of Wheel Loader Transmissions. $\mathrm{PhD}$ thesis, Linköping University, 2015.

[55] C. E. Nino-Baron, A. R. Tariq, G. Zhu, and E. G. Strangas. Trajectory optimization for the engine-generator operation of a series hybrid electric vehicle. Vehicular Technology, IEEE Transactions on, 60(6):2438-2447, 2011.

[56] J. Nocedal and S. Wright. Numerical optimization. Springer Science \& Business Media, 2006.

[57] M. Nordin, J. Galic, and P. Gutman. New models for backlash and gear play. International journal of adaptive control and signal processing, 11(1):49-63, 1997.

[58] S. Park, K. Alam, Y. Jeong, C. D. Lee, and S. Y. Yang. Modeling and simulation of hydraulic system for a wheel loader using amesim. In ICCASSICE, 2009, pages 2991-2996. IEEE, 2009.

[59] M. Patterson and A. Rao. Gpops-ii: A matlab software for solving multiplephase optimal control problems using hp-adaptive gaussian quadrature collocation methods and sparse nonlinear programming. ACM Trans. Math. Softw., 41(1):1:1-1:37, Oct. 2014.

[60] M. Pettersson. Driveline Modeling and Control. PhD thesis, Linköpings Universitet, May 1997.

[61] M. Pettersson and L. Nielsen. Gear shifting by engine control. IEEE Transactions Control Systems Technology, 8(3):495-507, May 2000.

[62] L. S. Pontryagin. Mathematical theory of optimal processes. CRC Press, 1987.

[63] S. Sarata. Model-based task planning for loading operation in mining. In Intelligent Robots and Systems, 2001. Proceedings. 2001 IEEE/RSJ International Conference on, volume 1, pages 439-445. IEEE, 2001.

[64] S. Sarata, N. Koyachi, T. Tsubouchi, H. Osumi, M. Kurisu, and K. Sugawara. Development of autonomous system for loading operation by wheel loader. In Proceedings of the 23rd International Symposium on Automation and Robotics in Construction, pages 466-471, 2006. 
[65] S. Sarata, H. Osumi, Y. Kawai, and F. Tomita. Trajectory arrangement based on resistance force and shape of pile at scooping motion. In Robotics and Automation, 2004. Proceedings. ICRA'04. 2004 IEEE International Conference on, volume 4, pages 3488-3493. IEEE, 2004.

[66] S. Sarata, Y. Weeramhaeng, A. Horiguchi, and T. Tsubouchi. V shape path generation for loading operation by wheel loader. In Field and Service Robotics, pages 591-602. Springer, 2006.

[67] S. Sarata, Y. Weeramhaeng, and T. Tsubouchi. Approach path generation to scooping position for wheel loader. In Robotics and Automation, 2005. ICRA 2005. Proceedings of the 2005 IEEE International Conference on, pages 1809-1814. IEEE, 2005.

[68] S. Sarata, Y. Weeramhaeng, and T. Tsubouchi. Planning of scooping position and approach path for loading operation by wheel loader. In Proceedings of the International Symposium on Automation and Robotics in Construction, Ferrara, Italy, 2005.

[69] H. P. Schöner. Automotive mechatronics. Control engineering practice, 12(11):1343-1351, 2004.

[70] J. F. Sherman. Integrated hybrid transmission with inertia assisted launch, Feb. 8 1994. US Patent 5,285,111.

[71] M. Sivertsson and L. Eriksson. Modeling for optimal control: A validated diesel-electric powertrain model. In SIMS 2014 - 55th International Conference on Simulation and Modelling, Aalborg, Denmark, 2014.

[72] M. Sivertsson and L. Eriksson. Model and discretization impact on oscillatory optimal control for a diesel-electric powertrain. In 4th IFAC Workshop on Engine and Powertrain Control, Simulation and Modeling ECOSM'15, Columbus, USA, 2015.

[73] M. Sivertsson and L. Eriksson. Optimal stationary control of diesel engines using periodic control. Proceedings of the Institution of Mechanical Engineers Part D Journal of Automobile Engineering, 2016.

[74] Z. Sun and K. Hebbale. Challenges and opportunities in automotive transmission control. In American Control Conference, 2005. Proceedings of the 2005, pages 3284-3289. IEEE, 2005.

[75] H. Takahashi and Y. Konishi. Path generation for autonomous locomotion of articulated steering wheel loader. Computer-Aided Civil and Infrastructure Engineering, 16(3):159-168, 2001.

[76] S. Thornton, G. Pietron, D. Yanakiev, J. McCallum, and A. Annaswamy. Hydraulic clutch modeling for automotive control. In Decision and Control (CDC), 2013 IEEE 52nd Annual Conference on, pages 2828-2833. IEEE, 2013. 
[77] T. Tokura, T. Asami, Y. Hasegawa, T. Sugimura, K. Kono, and K. Aoki. Development of smooth up-shift control technology for automatic transmissions with integrated control of engine and automatic transmission. 2007.

[78] TOMLAB. PROPT - Matlab Optimal Control Software, "http://www . tomdyn.com/".

[79] VOLVO A40G. articulated hauler product brochure, "https: //www . volvoce.com/SiteCollectionDocuments/VCE/Documents\% 20Global/articulated\%20haulers/Brochure_A35GFS_A40GFS_T4F_ EN_21_20040116_C_2015.11.pdf", 2016.

[80] Volvo Construction Equipment. Products: Wheel Loaders, "http://www. volvoce.com/constructionequipment/na/en-us/ products/wheelloaders/wheelloaders/Pages/introduction.aspx", 2016.

[81] VOLVO L220G. wheel loader product brochure, "http://www. volvoce. com/SiteCollectionDocuments/VCE/Documents $\% 20 \mathrm{Global} /$ wheel $\%$ 201oaders/ProductBrochure_L150G_L180G_L220G_EN_21_20023724-C_ 2012.04.pdf", 2016.

[82] A. Wächter and L. T. Biegler. On the implementation of an interiorpoint filter line-search algorithm for large-scale nonlinear programming. Mathematical programming, 106(1):25-57, 2006.

[83] G. Wagner. Application of transmission systems for different driveline configurations in passenger cars. SAE Technical Paper 2001-01-0882, 2001.

[84] J. Wahlström and L. Eriksson. Modelling diesel engines with a variablegeometry turbocharger and exhaust gas recirculation by optimization of model parameters for capturing non-linear system dynamics. Proceedings of the Institution of Mechanical Engineers, Part D, Journal of Automobile Engineering, 225(7):960-986, 2011.

[85] J. Walström and L. Eriksson. Modeling engines with a variable-geometry turbocharger and exhaust gas recirculation by optimization of model parameters for capturing non-linear system dynamics. Proceedings of the Institution of Mechanical Engineers, Part D, Journal of Automobile Engineering, 225:960-986, 2011.

[86] R. Zanasi, A. Visconti, G. Sandoni, and R. Morselli. Dynamic modeling and control of a car transmission system. In Advanced Intelligent Mechatronics, 2001. Proceedings. 2001 IEEE/ASME International Conference on, volume 1, pages 416-421. IEEE, 2001. 

Papers 



\section{Papers}

The articles associated with this thesis have been removed for copyright reasons. For more details about these see:

http://urn.kb.se/resolve?urn=urn:nbn:se:liu:diva-128002 

Linköping studies in science and technology. Dissertations.

Division of Vehicular Systems

Department of Electrical Engineering

Linköping University

No. 1 Magnus Pettersson, Driveline Modeling and Control, 1997

No. 2 Lars Eriksson, Spark Advance Modeling and Control, 1999

No. 3 Mattias Nyberg, Model Based Fault Diagnosis: Methods, Theory, and Automotive Engine Applications, 1999

No. 4 Erik Frisk, Residual Generation for Fault Diagnosis, 2001

No. 5 Per Andersson, Air Charge Estimation in Turbocharged Spark Ignition Engines, 2005

No. 6 Mattias Krysander, Design and Analysis of Diagnosis Systems Using Structural Methods, 2006

No. 7 Jonas Biteus, Fault Isolation in Distributed Embedded Systems, 2007

No. 8 Ylva Nilsson, Modelling for Fuel Optimal Control of a Variable Compression Engine, 2007

No. 9 Markus Klein, Single-Zone Cylinder Pressure Modeling and Estimation for Heat Release Analysis of SI Engines, 2007

No. 10 Anders Fröberg, Efficient Simulation and Optimal Control for Vehicle Propulsion, 2008

No. 11 Per Öberg, A DAE Formulation for Multi-Zone Thermodynamic Models and its Application to CVCP Engines, 2009

No. 12 Johan Wahlström, Control of EGR and VGT for Emission Control and Pumping Work Minimization in Diesel Engines, 2009

No. 13 Anna Pernestål, Probabilistic Fault Diagnosis with Automotive Applications, 2009

No. 14 Erik Hellström, Look-ahead Control of Heavy Vehicles, 2010

No. 15 Erik Höckerdal, Model Error Compensation in ODE and DAE Estimators with Automotive Engine Applications, 2011

No. 16 Carl Svärd, Methods for Automated Design of Fault Detection and Isolation Systems with Automotive Applications, 2012.

No. 17 Oskar Leufvén, Modeling for control of centrifugal compressors, 2013 .

No. 18 Christofer Sundström, Model Based Vehicle Level Diagnosis for Hybrid Electric Vehicles, 2014. 
No. 19 Andreas Thomasson, Modeling and control of actuators and co-surge in turbocharged engines, 2014.

No. 20 Emil Larsson, Model Based Diagnosis and Supervision of Industrial Gas Turbines, 2014.

No. 21 Andreas Myklebust, Dry Clutch Modeling, Estimation, and Control, 2014.

No. 22 Peter Nyberg, Evaluation, Generation, and Transformation of Driving Cycles., 2015.

No. 23 Daniel Jung, Diagnosability Performance Analysis of Models and Fault Detectors., 2015.

No. 24 Tomas Nilsson, Optimal Engine Operation in a Multi-Mode CVT Wheel Loader, 2015.

No. 25 Martin Sivertsson, Optimal Control of Electrified Powertrains., 2015. 


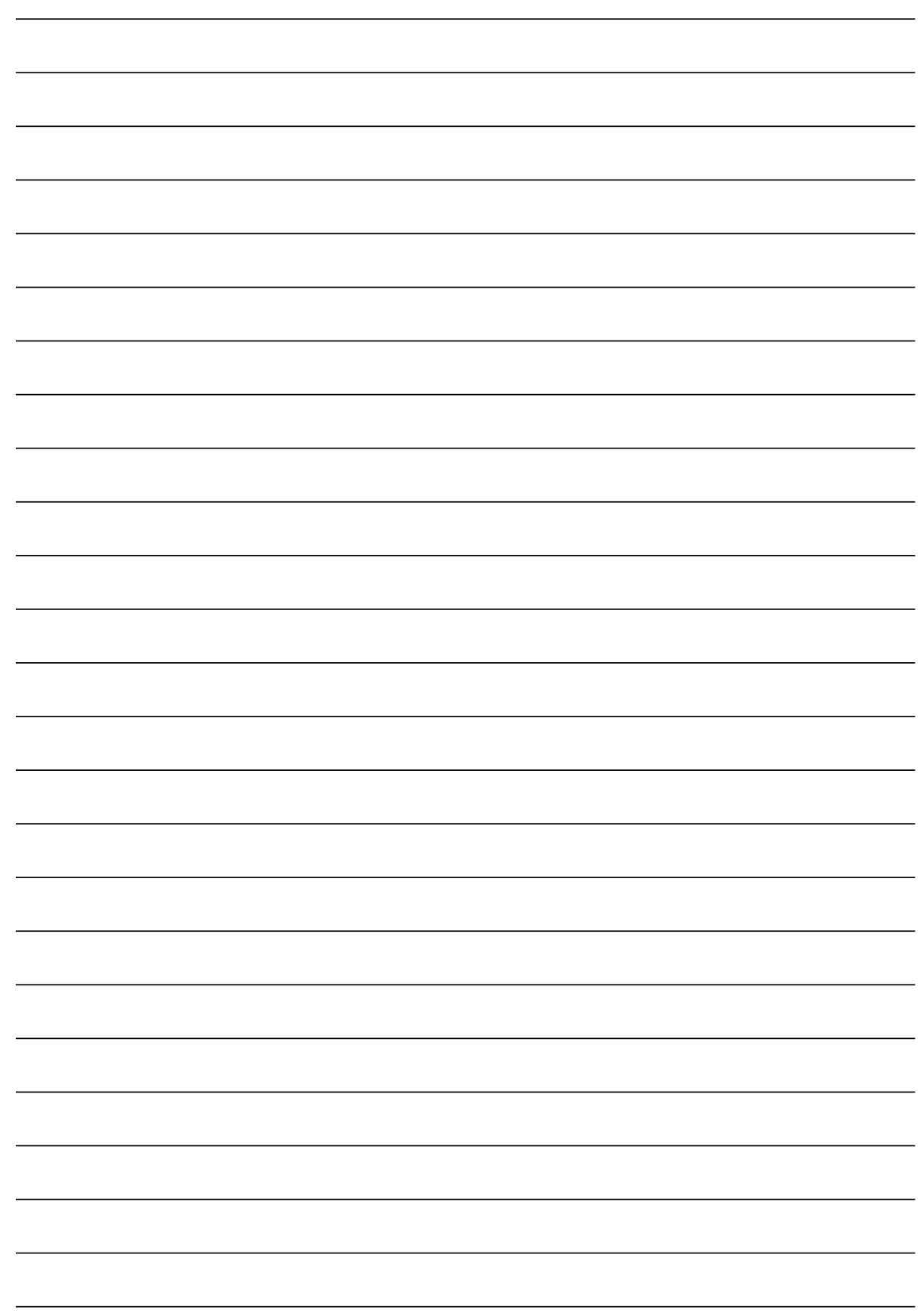




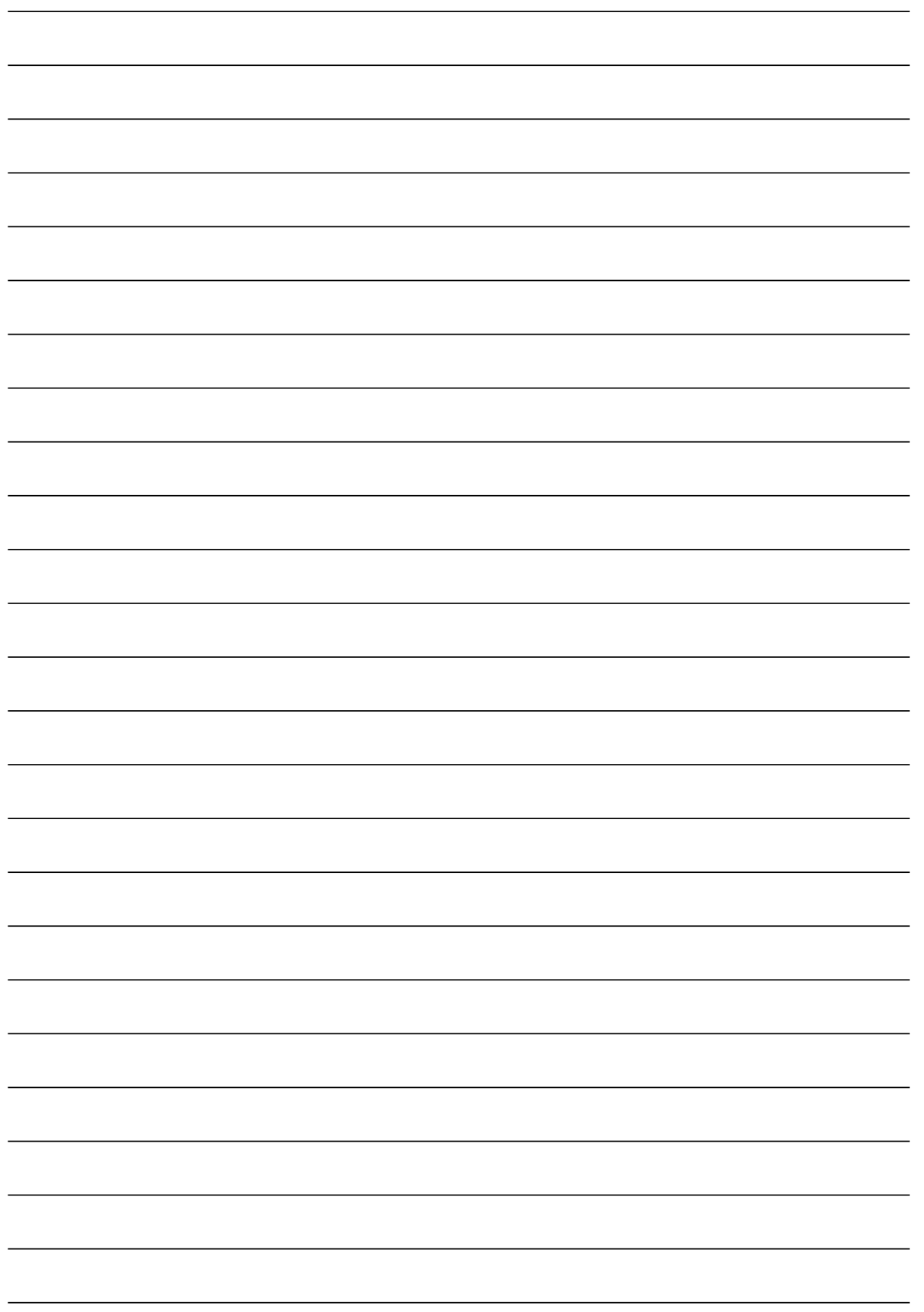

